\title{
History of Science and Science Education: The Uses of Old Instruments and Developing Institutions in Developing New Conceptions
}

\author{
Peter Heering1 ${ }^{1}$ Ian Winchester ${ }^{2}$
}

Published online: 9 April 2015

(C) Springer Science+Business Media Dordrecht 2015

This issue 2015 Volume 1 and the one that precedes it 2014 Volumes 3 \& 4 consist of a number of selected papers that were initially presented at the International Conference for the History of Science in Science Education (ICHSSE). This particular meeting, being the ninth in this series, took place in Flensburg (Germany) in 2012 and was devoted to discuss questions on enabling scientific understanding through historical instruments and experiments in formal and non-formal learning environments. The entire conference series originated from collaboration between Arthur Stinner (University of Manitoba) and Jürgen Teichmann (Deutsches Museum Munich). They established a series of meetings that aimed at familiarizing science teachers with topics from the history of science. This collection of papers in these two volumes are dedicated to the memory of Arthur Stinner, who unexpectedly died in 2014, and honour his large contribution to our common interests as science educators.

The Flensburg conference brought together science education researchers with historians of science in order to improve the interdisciplinary discourse of these groups. Consequently, the papers published in this issue can also be characterized by their interdisciplinary approach towards a history-based or historically informed science education. The different approaches towards the topic of the conference is also reflected by the papers in this special issue.

The grouping of papers that form the earlier volume involve authors who are concerned to discuss original approaches to science education in which an historical component is important. The authors of the present volume share a focus on the

Ian Winchester

winchest@ucalgary.ca

1 University of Flensburg, Flensburg, Germany

2 University of Calgary, Calgary, Canada 
educational potential of historical instruments. These could be kept in science museums or science centers - this would in some respect be the classical way to involve historical instruments into science education. Yet, we find also other approaches which either discuss a combination of classroom activities and field trips to museums, or bring instruments completely into the classroom. The collection of papers that share this interest will form the present volume of this collection. The contributions of Peter Heering, Don Metz, Juergen Teichmann, David Rhees, Gudrun Wolfschmidt and the paper jointly by Lidia Vernardizzi (Falomo) and Gabriela Albanezi appear in this volume and we will comment briefly on each.

Peter Heering and his colleagues provide historical instruments (mainly reconstructions) for schools. However, the focus of their approach lies in using these instruments as a basis for instruments that are to be built by the students themselves. Consequently, the focus of this approach lies more on the making of the scientific instruments themselves. David Rhees presents the Bakken Museum and its educational program. In doing so, he provides not only detailed education about how things presently are but also about its historical development. This is a remarkable institution with many unique features that is a great potential resource to teachers and students of science alike. In a similar vein Juergen Teichmann discusses the development of the educational program of one of the largest science museums in the world, the Deutsches Museum in Munich. Teichmann shows in his contribution how educational activities and exhibition objects go hand in hand. Moreover, he also provides information about a variety of exemplary objects that are on exhibit in the Deutsches Museum and which are supported by particular educational activities and materials. Teichmann also shows how the educational program of the museum has developed over time. Gudrun Wolfschmidt shows in her contribution the educational potential of transforming a research site (an observatory) into a museology site with a strong educational agenda. Not surprisingly, the main topic of the educational activities lies in the field of astronomy. Yet it is remarkable how broad the approach is and what programs are offered for students of different age groups. Moreover, some of these programs aim at teaching science through history while others focus more on teaching the history of science. As a consequence the broadness of her examples provide a vivid impression of the achievements that can be made through the educational programs realized at the observatory.

In a somewhat different vein Lidia Falomo and Gabriele Albanesi provide us with a case study in which informal learning took place on a particular occasion, namely the 650th anniversary of the founding of the University of Pavia. They show on the one hand how art and science can be interrelated in a particular and fruitful manner but how, on the other hand, educational programs can be made appropriate for student of very different age groups from pre-schoolers to those of lyceum or high school age. In this respect their example demonstrates nicely how learners can also become teachers, sharing the expertise they have developed with their peers. This paper demonstrates the potential of modern communication technologies in science education and how one can go beyond scientific narrative to the development of a singular informal educational project. 
These papers, taken together, both the ones included in this volume, 2015, Volume 1 and the ones in the previous volume, 2014, Volumes $3 \& 4$, show the potential of the history of science for science education. They also demonstrate the interdisciplinary character that is required in order to use the full potential of the history and philosophy of science in educational settings. In this respect it becomes evident that this approach does not have to be limited either to formal educational settings or to informal ones. What appears to be particularly fruitful is the collaboration between these areas. In particular, these collaborations appear to enable educators to access the competencies of historians of science while such historians can bring their knowledge, competencies and understanding to illuminate educational situations and settings. From this point of view, these papers can be seen rather as starting points rather than closure. We clearly need more examples in this respect. And we need, too, a deeper analysis of the effects that result from such collaborations. As a first step these papers clearly form a basis that can enrich future research as well as future education. 